\title{
Crónicas de Filipinas
}

\author{
Por Alberto tauro
}

M A N I L A

Al dejar la cabina del avión, en el aeropuerto de Manila, percibimos claramente la presión de un vapor tibio que pronto se licuó en el rostro y las manos, a pesar de la brisa que parecía venir desde el mar próximo y ser apenas las 6.30 de la mañana. Pero alenté algún consuelo cuando supe que los más intensos calores, cercanos a los 40 grados, habían sido experimentados en la primera semana de junio; y que el ambiente refrescaría justamente al terminar este mes, cuando cempezasensa caer las lluvias. Y sólo entonces, al revisar una guíg, hallé la indicación que la experiencia y la costumbre aconsejan: "Para vestido de calle son mejores las camisas con manga corta, de rayón o algodón... $y$ en las reuniones formales los extranjeros han empezado a adoptar la Barong Tagalog, la camisa filipina usual en los negocios y en las fiestas". Es ésta una camisa blanca, de seda o algodón, con mangas largas, y que ostenta vistosos bordados -por ejemplo: flores, un paisaje tropical, una pelea de gallos- en la parte delantera, y algunos de sus motivos en el cuello y los puños.

Todavía se conservam en Manila algunas calesas, tiradas por jamelgos cansinos. Tienen lugar para dos personas $y$, desda luego, no son aconsejables para quienes lleven alguna prisa. Se diría que son para pasear a los niños, o para sentirse adormecido por el balanceo mientras la ciudad discurre ante la vista con el dinamismo de un film, o para que dos personas bien avenidas se sientan fuera del tiempo y del espacio. Es difícil pensar que conduzcan a alguna parte. Y sólo parece que circulan en las 
calles centrales, donde a veces se las ve unas tras otras, anacrónicamente detenidas por algún semáforo. Pero la realidad es muy distinta, porque algunas de ellas lucen desvencijadas. Constituyen un medio de trasporte popular, pues marchan airosamente a través de los malos caminos y aun por donde no los hay. Y como el precio de sus servicios está sujeto a un acuerdo con el calesero, pueden trasportar a largas distancias en forma menos onerosa que los taxis.

Si hay algo característico en el tránsito urbano de Manila, no son las calesas. Son centenares de jeeps, pintoresca y hábilmente adaptados para el trasporte de pasajeros: los jeepneys. Aparte del asiento delantero, tienen dos laterales, en los cuales se acomoda el público ingresando por la parte posterior. Pueden conducir de ocho a diez personas, debidamente protegidas del calor y de la lluvia, pues la carencia de ventanas les hace llegar un aire reconfortante, $y$ en caso de necesidad están provistas de cortinillas impermeables. Son muy versátiles y desafían pasmosamente las reglas del tránsito o la tranquilidad del pasajero novato: porque tan pronto cruzan de un lado a otro de la calle para dejar o recibir una persona, como atraviezan por los espacios inverosímiles que a veces dejan dos vehículos detenidos, o aceleran para recuperar el tiempo que estuvieron parados ante una luz roja o la voluntad de un policía. Muy significativo es leer la inscripción que algunos ostentan en la parte delantera, a la derecha del timón, y que revela todo un código de tránsito: "God bless us". Y en las esquinas, $o$ en los lugares donde aparece a]gún grupo, los conductores vocean el servicio que efectúan, y agregan una renovada algarabía a los ruidos de la calle.

Pero aun existe otra especie de vehículos, que recientemente ha aparecido en Manila y ya motiva crónicas periodísticas o reflexiones sobre los problemas que suele crear su circulación. Son triciclos, cuyo carro lateral ha sido adecuadamente preparada para el trasporte de uno o dos pasajeros. Se los ve en torno a los mercados, con sus variados y relucientes colores, con vistosos adornos que el viento hace ondear, y la sugestión de ternura que envuelven los nombres femeninos estampados en su parte delantera. No cubren rutas fijas, sino aquellas que se les requieran y a precios que oscilan en torno a los diez centavos. Sin embargo, no pueden competir con los taxis o los jeepneys: porque dependen de la energía o la resistencia de sus conductores, 
los cuales suelen ser adolescentes y aun niños. Lamentablemente sustraídos a las labores de la escuela, van risueños por esas calles, indiferentes a la fatiga y al calor, y a veces con el busto desnudo, alentados quizá por la satisfacción de ser independientes o de concurrir al precario sostenimiento de sus hogares. Revelan una saludable y promisora voluntad de vivir mediante su propio esfuerzo, aun aguzando el ingenio para hallar nuevas vetas de labor. Pero ofrecen un espectáculo deprimente, porque su ganancia se reduce tal vez a los centavos que no gastan en combustible. Y porque su nombre - pedicab-advierte que en ellos se da un retorno al empleo de la energía humana como fuerza de tracción.

Pues, así como la concurrencia de estos diversos vehículos da a las calles centrales una peculiar y polícroma animación, el estilo de las actividades comerciales pone una confusión de feria en los portales de la Avenida Rizal y el Boulevard Quezón, tanto como en las calles adyacentes. Los tenderos desbordan sus mercancías hacia la vereda y las ofrecen estentóreamente, llamando la atención del transeúnte a fín de hacerle apreciar la excelencia de algún artículo o la baratura de su precio. Y en las arcadas, $o$ al borde mismo de las tiendas, o ambulando entre los viandantes, se ve un enjambre de vendedores, que ofrecen periódicos, loterías, golosinas o baratijas. Desde los cafés o restaurantes, atendidos por jovencitas mestizas, emergen pizarrones con largas listas en las cuales aparecen las viandas del día y sus precios, en tanto que desde su interior se asocian a los ruidos callejeros los confusos ecos de una canción radiofónica. Un ciego apela a la caridad pública arrancando sones más o menos acordados a dos o tres instrumentos, y de tarde en tarde se ve mendigar también a niños y ancianas. Ante los cines contemplan algunos grupos las fotografías de los films, que en forma continuada se exhiben unas nueve veces cada día, desde las 8 de la mañana hasta las 11 de la noche. $Y$ es curioso advertir que esta pintoresca y abigarrada animación se mantiene a través de las horas laborables y no decae hasta muy entrada la noche.

A poca distancia, en el sector de la banca, el ritmo es muy distinto. La oferta comercial no persigue al cliente en el curso de sus andanzas, sino intenta atraerlo con una exhibición discreta. Los cafés invitan a trasponer la puerta, brindando el confort del aire acondicionado. $Y$ las veredas no se hallan congestionadas. 
Pero aquel es un sector pequeño, una pausa en el tráfago, un espacio de tonos tenues en el cuadro de intenso colorido que la ciudad ofrece a la vista.

Manila es, evidentemente, una ciudad donde campean los contrastes. No solo porque en sus calles transitan simultáneamente ruidosos autobuses - desde los cuales pregonan su ruta las agudas voces de las jovencitas que fungen como cobradoras-, taxis y jeepneys veloces, calesas de viejos tiempos y triciclos propulsados por adolescentes: ni por las calidades, métodos y ritmos que es posible confrontar en el comercio, a veces de una vereda a otra, $o$ al voltear una esquina. Lo digo en primer término, porque es la sede del gobierno; y, no obstante, la capital es Quezon City, cuyo límite jurisdiccional se yergue airosamente a pocos kilómetros del centro de Manila, en una planicie hacia la cual dirige sus tentáculos el desarrollo urbano y fabril de la secular ciudad. En rigor, apenas ha dejado de ser un proyecto la nueva fundación, pues solo se han levantado en su área tres construcciones gubernativas $y$, en sectores aislados, los vastos edificios de la Universidad de Filipinas y una urbanización inicialmente destinada para los empleados; cuenta con magníficas avenidas troncales, pero sus calles subsidiarias existen sólo en el plano o en el barrio de la burocracia carecen de veredas. Pero la nueva ciudad llegará ia completarse ye expresará las ambiciones administrativas, urbanas y arquitectónicas de los años inmediatamente posteriores a to independencia de Filipinas. Y entonces no sorá posible distinguir dónde acaba de languidecer la vieja urbe, ni dónde empieza la erección actual, porque ambas se habrán fusionado y en su continuidad se ofrecerá un testimonio de la lógica hilación de los tiempos.

En dirección opuesta a Quezón City se extienden las calles arboladas de Makati y Pasay City, flanqueadas por muros que ocultan la holgura de hermosas casonas, o hacia las cuales afluye el color y la gracia de sobrias viviendas. En ellas se refleja un ansia de modernidad, que no desea ajustarse a la limitada herencia del pasado y pugna por desenvolverse racionalmente. Es la misma ansia que aparece en las líneas altivas de las nuevas edificaciones que hoy se alzan sobre los solares desvastados durante la II Guerra Mundial, y en la sólida estructura de los puentes que unen la ciudad a despecho de las quietas aguas del río Pasig. $Y$ es curioso anotar que uno de estos puentes -quizá el más am- 
plio y extenso, por hallarse cerca de la desembocadura del río y haber sido destinado para servir al tráfico del puerto- está olvidado desde su terminación. En tanto que las maderas de un puente provisional crujen y se cimbran a poca distancia, bajo el peso de vehículos de carga y pasajeros, aquella vía de hierro y cemento sólo es recorrida por las lluvias que se encargan de limpiarla. Se comenta, risueñamente, que un buen día se doblega. rá la crujiente vía que se halla en uso, y el estupor ocasionado por la desgracia precipitará la definitiva apertura de la que se ha construído para sustituirla. Y una dilación tan extraña, tan opuesta a las direcciones del progreso, reconoce una causa muy discutible pero eficiente: si se abre al tránsito el nuevo puente es necesario destruir un improvisado barrio, donde viven hacinadas numerosas familias de muy humilde condición económica y sócial, y ninguna autoridad política se atreve a favorecer el desalojo porque se presume que tal medida restaría centenares o millares de votos al partido que controla el gobierno.

Manila fue oficialmente fundada el 24 de junio de 1571, por el conquistador Miguel López de Legazpi, en el emplazamiento donde ejerció su soberanía un rajá mahometano. Para defender la entrada del río Pasig, algún lejano antecesor había levantado allí un recio cerco de madera, sobre el cual fueron entonces instalados unos elocuentes cañones de broncee Pocos años después, los gobernadores Santiago de Vera (1584-1590) y Gómez Pérez Dasmariñas (1590-1593) fortificaron la ciudad con un amplio y sólido muro de piedra, porque era indispensable defenderla contra las incursiones que intentaban lesionar su posición como estratégico centro del comercio con Oriente. En la punta formada por la bahía y el río se levantó entonces el fuerte de Santiago $\longrightarrow$ Fort Santiago, como se le llama ahora, en armonía con la nomenclatura adoptada durante la dominación estadounidense-, y entre los muros se alzaron las casas del gobernador y el cabildo; la catedral; iglesias y conventos de jesuítas, agustinos y dominicos, clarisas y carmelitas; severas mansiones con zaguanes hospitalarios y amplios balcones. Mientras la ciudad se extendía en su torno, luciendo edificios con esbeltas columnatas y elegantes cornisas, o multiplicando precarias viviendas de madera, entre los muros parecía haberse detenido el tiempo. Las calles eran quietas y familiares, y ostentaban la jerarquía de los años en el color gris o rosáceo de sus piedras. Pero todo aquello ha desapa- 
recido,por efecto de las rudas batallas libradas en el curso de la II Guerra Mundial para decidir la posesión de Manila y, muy especialmente, durante el contraataque norteamericano llevado a cabo en febrero de 1945, pues las fuerzas japonesas hicieron do aquella ciudadela su último y desesperado reducto. Pasaron largos días de intenso bombardeo antes de que se abrieran en los muros las brechas que requería el asalto final. Sólo quedaron entonces amontonamientos de ruinas calcinadas, entre los cuales se elevaba alguna pared vacilante, y fue menester el auxilio de grandes máquinas para remover todo peligro. La vieja población española, amurallada, quedó convertida en un campo llano. Como solitario testigo de su extraordinario carácter apenas se conserva el templo de San Agustín, y de su recia estructura hablan todavía algunos restos de los muros que la guarnecían. Así ha desaparecido la ciudad erigida en el Oriente por la audacia de los conquistadores españoles del siglo XVI. Manila ha perdido así su vieja estampa, su color antiguo y mucho de su leyenda.

A la sombra de la desvastación causada por la guerra se han formado numerosos agrupamientos de viviendas populares. En la zona del puerto han cegado calles, y obstruyen la utilización del nuevo puente; entre las ruinas de la ciudadela hispánica reptan a pocos metros de la nueva catedral; y dondequiera existe un solar descuidado por sus dueños, conforman un lamentable abigarramiento. De maderas usadas, ennegrecidas por la humedad de las lluvias y el humeique despiden das cocinas, suelen estar protegidas por techos de calamina, y se levantan sobre pilares que las aislan del suelo barroso. Son pequeñas, porque a sus moradores les basta una tarima para el reposo, una mesa y algunos bancos. Se advierte en algunas los artículos propios de un pequeño comercio; en otras, los trebejos de una modesta artesanía, - la actividad de un servicio doméstico; y, con frecuencia, la holganza. Las calles aledañas se pueblan con las voces de los chiquillos que huyen de la estrechez y la oscuridad de sus precarios hogares; y, a veces, con los variados colores de las ropas tendidas sobre el césped o las matas silvestres. Pero en esa sórdidez no faltan lo detalles alentadores, porque a través de sus ventanas brilla la coquetería de un espejo, o destaca la camisa impecable que deberá ser usada al día siguiente, o luce alguna guitarra cuyas notas acompañarán las palabras de una dolida canción.

Desde hace siglos confronta Manila otra faz interesante de su destino, a saber: la penetración $y$ el creciente poder económi- 
co de los chinos. Dominan el comercio minorista y, en consecuencia, la distribución y los precios de los productos esenciales para la vida. Trabajan activamente en la importación y la exportación, han establecido un banco y una cámara de comercio. Dominan la industria hotelera, pues poseen dos de los tres hoteles de primera clase, y son de ellos casi todos los de segunda y tercera categorías, así como restaurantes, pastelerías y fábricas de artículos alimenticios. Poseen numerosas salas cinematográficas, y algunas de ellas consagradas a sus propios espectáculos. Ejercen los más variados oficios. Imponen algunas de sus costumbres. Y para detener su expansión económica se ha extendido a todos los extranjeros una equívoca inhabilitación para adquirir bienes inmuebles. O se intenta limitar el ingreso de los chinos al país, aunque es prácticamente imposible mantener en torno a las islas una vigilancia que impida el tráfico clandestino, desde Formosa o la costa continental. O se les envuelve en el ocultamiento y la evasión de divisas. Pero nada entorpece la vida en el barrio donde agrupan sus viviendas, y donde se imponen a la vista los anuncios escritos en su idioma. Sus negocios siguen creciendo, y su rostro se mantiene inexpresivo tras el humo de su cigarrillo.

\section{SOBRE LA LENGUA NACIONAL DE FILIPINAS}

Aunque fue en "I52lyecuando Hernando des Magallanes hizo ondear la bandera española en el archipiélago; y dos décadas más tarde, cuando Ruy López de Villalobos aplicó el nombre de Filipinas a algunas de sus islas, para honrar al príncipe que sucedería en el trono a Carlos I; sólo en 1565 se estableció el dominio de España sobre aquellos belicosos pueblos, debido a los trabajos hábilmente cumplidos por Miguel López de Legazpi. Con intensas alternativas y muy variada fortuna, los peninsulares man. tuvieron su soberania hasta 1898, año en el cual cedieron a Estados Unidos el gobierno de Filipinas, en virtud del tratado que puso término a la guerra entre aquellos países y que fue suscrito en París el 10 de diciembre. En verdad, España había perdido ya el control de las islas, pues en 1898 había estallado una vasta revuelta de los autonomistas, que condujo a la organización de un gobierno presidido por el general Emilio Aguinaldo; y Estados Unidos hubo de sostener costosas operaciones militares antes de obtener, en abril de 1902, el total sometimiento de las fuerzas re- 
publicanas, e iniciar una etapa destinada a procurar la educación del pueblo en las responsabilidades del sistema representativo y la posterior satisfacción de sus aspiraciones nacionales. Inmediatamente se llevó a cabo una enérgica reorganización del gobierno; y empezó a cumplirse un vasto programa escolar, basado $\in \mathrm{n}$ la aplicación del inglés. Más de 5,000 maestros fueron distribuídos en todo el país, para supervigilar las labores de las escuelas y la enseñanza de la lengua oficial. Pero trascurrieron los años $y$, aceptando los pronunciamientos de los filipinos en favor de la independencia, el 23 de marzo de 1935 aprobó Franklin D. Roosevelt una transitoria asociación -commomwealth-que al cabo de diez años sería seguida por un total retiro de la soberanía norteamericana. Pero este plazo sufrió una ligera dilación, por efecto de la ocupación japonesa y el restablecimiento de la paz, y sólo el 4 de julio de 1946 iniciose la vida independiente de Filipinas.

Al. cabo de tal trayectoria, ¿qué lengua habla con preferencia el pueblo filipino? Pues, no es el español, a pesar de haber sido "impuesto" su uso durante 333 años -o sea, desde la llegada de Legazpi hasta la suscrición del tratado de París-. Es fácil comprobar que, aún en esos tiempos, las prensas de Manila imprimieron numerosos vocabularios y gramáticas de las lenguas nativas, así como textos de doctrina escritos en las mismas, al igual de lo que cocurriócene Américálelos dirigentes de la lucha emancipadora efectuaron su propaganda oral mediante las lenguas nativas, y el lema del primer levantamiento popular - Kataastaasan Kagalang-galang Katipunan ñg mañga Anak ñg Bayan, o sea, "la más alta y la más respetable Asociación de los Hijos del Pueblo" - fue expresado en una de ellas; de manera que el español no llegó a generalizarse, y en la actualidad se estima que lo habla únicamente el 3 por ciento de la población. Tampoco puede afirmarse que el pueblo filipino prefiera el inglés; en verdad, está muy lejos de ser éste un común instrumento de expresión, no obstante haberse extendido rápidamente su conocimiento, gracias a su empleo compulsivo en las escuelas, en la documentación pública y privada, y en la lectura popular; y el censo de 1948 advertía, precisamente, que sólo el 37.2 por ciento de la población apelaba a esta lengua en sus relaciones cotidianas. De allí que el establecimiento del commonwealth, y la consagración de la independencia, plantearan la necesidad de pro- 
curar la unidad del país mediante la adopción de una lengua nacional, cuyo uso pudiera extenderse sin provocar una resistencia sentimental de los pueblos. Discutióse la conveniencia de favorecer con la elección al español o al inglés; pero se alegó que la mayoría de la población no podía expresarse plenamente en esas lenguas, por ser extranjeras, y ver representạdo en ellas el desconocimiento de sus derechos soberanos. Tras largo y equilibrado estudio se llegó a señalar el tagalog como lengua nacional. Y según lo estipula hoy la constitución, Filipinas es el único país que tiene tres lenguas oficiales: tagalog, inglés y español.

En apoyo de esta decisión, el representante Norberto Romualdez adujo coincidentes experiencias de otros pueblos, sin advertir que sus particulares circunstancias hacian discutible homologarlas con el caso filipino. Sus reflexiones fueron las siguientes: "La selección y el definido predominio de un dialecto sobre otros en un país, ha sido la historia general de las lenguas adoptadas como medio nacional de expresión. Así sucedió en Italia cuando el dialecto del Lacio, latín, obtuvo su preponderancia debido al poder militar y político de Roma; en Francia, cuando París fue hecha capital de la nación en el siglo X, y gracias a ello el dialecto parisino alcanzó una situación de supremacía sobre los otros dialectos franceses del norte y el sur, incluyendo el provenzal; en España, cuando el dialecto central, el castellano, fue impuesto sobre los demás dialectos de la península, a consecuencia de la consolidación de lós reinos de Castilla en el siglo XI; en Alemania, donde el latín había jugado un rol supremo entre las diversas ramas de dialectos alemanes, y uno de estos forzó su camino hacia el uso nacional, suplantando al latín en los diversos campos de la cultura humana; en Inglaterra, donde la derrota de las invasiones germánicas, después de que habían implantado varios dialectos en el siglo $V$, y bajo el reinado de los normandos, fue adoptado el dialecto del pueblo común como el lenguaje nacional". Y luego subrayó que existían tres factores favorables, para precipitar la solución del caso, a saber: la necesidad de una lengua nacional, el apoyo oficial a su difusión, y la posibilidad de encontrar un dialecto nativo que estuviera suficientemente desarrollado y pudiera satisfacer las exigencias de una lengua nacional.

Ahora bien, el tagalog no es, en rigor, sino uno de los 86 dialectos que - con 187 variedades reconocidas - se hablan en las 
islas. A juzgar por el censo de 1948, sólo era medio usual de expresión para el 37.1, por ciento de la población. Pero además de revelar tal cifra una recia supervivencia de esa lengua nativa, y su aptitud para competir en la vida cotidiana con un idioma tan favorecido por la acción del estado como el inglés, la elección tuvo en cuenta otros hechos. El tagalog es el lenguaje predominante en Luzón, la isla más grande del archipiélago; es el que se usa comúnmente en Manila, centro del gobierno y de las más intensas actividades económicas e industriales, sociales y culturales; y es también el que posee más copiosas y ricas expresiones folklóricas y literarias. Por añadidura, se atendió a las palmarias semejanzas entre el tagalog y otros dialectos, y se estableció que, en muchos casos, los cultivadores de éstos pueden adquirir un eficiente conocimiento de aquel en un período de tres meses.

En cierta manera, el proceso fue metódico y lógico. Ante todo, un acto legislativo creó, el 13 de noviembre de 1936, el Instituto de la Lengua Nacional, al cual se encargó efectuar un estudío de los dialectos que fueran hablados por más de 500,000 personas, entendiéndose que si un dialecto cualquiera se limitaba a un núcleo demográfico menor se lo debía considerar como una variedad local de los predominantes. Así quedó reducido sólo a ocho el número de los díalectos que se debía considerar. Y para asegurar la Jlucidez de la conclusión a que pudiese llegar el Instituto de la Lengua Nacional, sus miembros fueron elegidos como representantes de las más importantes regiones del país y de sus respectivos dialectos. El 9 de noviembre de 1937 recomendaron la adopción del tagalog como base de la lengua nacional, y el presidente Manuel L. Quezón resolvió el 30 de diciembre que su adopción se haría efectiva a los dos años. En tanto, debía efectuarse una clasificación de las palabras usadas en los diferentes dialectos, a fin de enriquecer el básico mediante la incorporación de los elementos utilizables; y, sucesivamente, debía procederse a la compilación de un diccionario y una gramática. Tales tareas fueron oportunamente cumplidas $y$, en consecuencia, el tagalog se convirtió oficialmente en la base de la lengua nacional, desde el 31 de diciembre de 1939. En forma transitoria se lo utilizó en las escuelas como un medio de instrucción, por acuerdo del gobierno auspiciado por los japoneses durante la II Guerra Mundial. Y en 1956 adoptose una reforma educativa, en 
virtud de la cual la enseñanza primaria debe impartirse durante los dos primeros años en los principales dialectos - cebuano, ilocano, hiligaynon, bicol, samar-leyte, pampango, pangasinan $y$, además, tausug e ibonag- y, desde el tercer año, en tagalog, cuyo aprendizaje se facilita mediante el conocimiento adecuado de los otros dialectos enunciados, porque su estrecha relación ha sido determinada a través del estudio comparado.

Hoy es el tagalog un medio de expresión usual en el trato familiar. Se lo difunde en el teatro y el cine, en las trasmisiones radiofónicas y numerosos órganos de prensa. Alterna con el inglés en las inscripciones de las oficinas públicas y las indicaciones del tránsito urbano. Y cabe plantear algunas interrogaciones, para asomarse a los cambios que puede traer el acelerado paso de los tiempos. Pues, si la difusión oficial del español y el inglés no bastó para hacer olvidar una lengua como el tagalog ¿podrá determinar la difusión oficial de ésta el abandono relativo o absoluto de aquellas? $\mathrm{Si}$ el rasante nacionalismo de Filipinas pugna por afianzar la posición del país en el sud-este de Asia, cla adopción de la lengua nacional conducirá a fortalecer los vínculos continentales del pueblo filipino con los pueblos de la misma región? Si a través de las dominaciones española y norteamericana, y principalmente en virtud de los respectivos idiomas, se consideraba a Filipinas como el único país donde se habían fusionado las culturas de Oriente y Occidente, iel uso progresivamente exclusivo del tagalog "ocasionará una lạlteración de la faz cultural del país?

\section{SOCIEDAD Y EDUCACION EN FILIPINAS}

Tres hechos fundamentales condicionan la educación primaria en Filipinas: 19, el predominante agrarismo de la actividad económica, al cual se encuentra ligado nada menos que el 90 por ciento de la población; $2 \%$, la circunstancia de reconocerse en el país tres lenguas oficiales y haberse designado, como medios de instrucción, nueve de los 86 dialectos reconocidos; y 39 , la existencia de minorías y colectividades diferenciadas por su origen étnico, su filiación religiosa y su elemental grado de civilización, tales como los chinos, los musulmanes y las tribus que conservan sus creencias ancestrales. Es fácil comprender por que admite el Director de Escuelas Públicas, doctor Benigno Aldana -en The 
Philippine Public Educational System-, que el sistema de educación tiene mil y un problemas: "algunos se prestan a una solución expeditiva, en tanto que otros parecen estar siempre inadecuadamente solucionados, no importa cuánto esfuerzo se haga 'para analizarlos y aplicar medidas que los remedien". En verdad, lo contrario sería insólito. Porque las previsiones escolares deben ajustarse a la realidad social, y ésta se halla afectada en Filipinas por la continuada separación y la áspera divergencia que mantienen algunos de sus elementos formativos, y por la herogeneidad de las tradiciones y los medios de vida que a ellos corresponden. $Y$, en consecuencia, la abnegada labor del maestro es particularmente compleja y trascendente, porque no sólo debe actuar como trasmisor de conocimientos sino como artífice de la integración del país.

Según el censo efectuado en 1948, sólo el 24 por ciento de los habitantes vivía en los 1121 centros poblados que tenían gobierno local; y en 1959 se estima que la concentración urbana ha ascendido al 39 por ciento. Pero juzgamos que tales cifras no reflejan exactamente la realidad social, porque la mayor parte de esas poblaciones son "barrios" o comunidades rurales, y aún las ciudades lo son en cierta manera, aunque sea impresionante la expansión demográfica registrada en ellas durante el presente siglo. Por ejemplo: de 8560 habitantes que tenía Davao en 1903 , los aumentó a 111,263 en 1948, y hạ pasado a ser la tercera ciudad de Filipinásiconlos d 33,754 que sello estiman en 1959; pero sólo una tercera parte de dicha población es propiamente urbana y el resto se extiende en las zonas aledañas. Fenómeno semejante es el de Zamboanga, con 22,023 habitantes en 1903, aumentados a 103,317 en 1948 y estimados en 124,202 el año 1959. Y, como es fácil suponer, las circunstancias descritas afectan sensiblemente a la educación: 19, porque muchos niños suelen tener sus hogares a una distancia excesiva de la escuela, y muchas veces no existe trasporte conveniente o la economía familiar no permite pagarlo; $2^{\circ}$, porque la ubicación de las escuelas debe corresponder a la escasa densidad de las vastas zonas urbanas y las comunidades rurales, determinando su inevitable multiplicación y la consiguiente alza del costo del proceso educativo; y $3^{\circ}$, porque en muchas escuelas se reúne en un mismo salón, y a cargo del mismo profesor, a los pocos alumnos de dos años sucesivos, a quienes respectivamente se puede consagrar sólo 25 minutos en cada hora de trabajo escolar. 
La ley ha consagrado en Filipinas la obligatoriedad de la enseñanza primaria, como corresponde a los objetivos sociales de la educación moderna y a los postulados de la democracia política. Pero no ha podido ignorar las circunstancias especiales de su actual coyuntura y ha fijado algunas causas de excepción, entre las cuales se cuentan la distancia y las dificultades de trasporte entre el hogar y la escuela, la extrema pobreza de los padres y la consiguiente necesidad de que el niño efectúe alguna tarea económicamente productiva. $\mathrm{Y}$ esto es lógico, si se considera el bajo nivel de vida del trabajador agrícola, pues, aunque su salario mínimo se eleva a 2.30 pesos diarios, esta cifra es sólo un remoto indicio de sus ingresos efectivos. En verdad, son proporcionalmente reducidos cuando no alcanza a concluir su tarea; o cuando se le asigna 23 centavos por hora, e indirectamente se le sujeta a una jornada de 10 horas; o cuando se computa las ganancias de un año entero, que diversas fuentes hacen ascender a 1107.6 horas -cf. Philippine Studies: junio de 1955- o al 60 por ciento de los días del año, y, en consecuencia, puede oscilar entre 4.55 y 9.38 pesos por semana, que apenas representan el valor de una alimentación familiar más o menos sobria y no dejan el margen indispensable para vestido, medicinas, requerimientos sociales o cultura. Y aunque la situación de los aparceros -tenants-y los pequeños propietarios es menos sombría, en cuanto pueden mejorarla mediante el desarrollo de su iniciativa y su esfuerzo, cabe observar que se hallan subordinados a las condiciones contractuales y a la capacidad de los mercados locales, y su débil posición los limita a la producción de consumo doméstico. Por tanto, es frecuente que no puedon cubrir el costo de los libros y útiles escolares, o atender siquiera a la presentación de los niños en la escuela; y desde el primero al sexto años de educación primaria se registra tal alejamiento de los alumnos que durante el curso de 1957-1958 hubo en el último sólo el 36.88 por ciento de los niños que entonces iniciaron sus estudios en las escuelas públicas -a saber, 318,477 y 890,059 inscritos, respectivamente- Al iniciarse las labores, cada escuela forma una relación de los alumnos que no han pedido su inscripción; los maestros acuden luego a visitarlos, a fin de obtener la cooperación de los padres para que sus hijos continúen sus estudios; y, entre las causas establecidas para justificar el hecho, sólo por excepción aparece mencionada la incompetencia o la pereza del niño, en tanto que la mayoría alegan pobreza y ocupaciones familiares. Pe- 
ro la propaganda efectuada por los maestros tiene alcances misionales, y gracias a ella se decide el retorno de muchos niños a la escuela.

No obstante la importancia fundamental de la agricultura en la vida económica de Filipinas, y el estrecho ligamen que con ella mantiene el 90 por ciento de la población, algunos índices educacionales permiten deducir que se la subestima como medio de progreso individual y social. Por ejemplo: no aparece ninguna de sus especialidades entre los cursos vocacionales suplementarios que se ofrece a los estudiantes de universidades y escuelas profesionales; y de éstos, que en 1957-1958 ascendieron a 249,573, sólo 10,372 - o sea, el 4.15 por ciento- siguieron estudios de agricultura, medicina veterinaria, forestación y pesquería. $O$ bien: de los alumnos graduados en las escuelas agrícolas vocacionales durante los 30 años comprendidos entre 1925 y 1955, una encuesta ha revelado que sólo 8 por ciento se consagraron íntegramente a las labores del campo y 6 por/ciento parcialmente, 12 por ciento siguieron cursos superiores de agricultura y 75 por ciento optaron por estudios y ocupaciones distintas. Antes que favorecer el desarrollo técnico y económico de las explotaciones agrícolas, tales índices parecen sugerir que la educación contribuye a definir la disconformidad que suscitan las condiciones de vida y de trabajo imperantes en el campo. Y aparte delos profesionales altamente especializados, que conducen los latifundios y las plantaciones industriales, están vinculados a la tierra los cultivadores que heredaron los conocimientos de sus mayores.

Igualmente decisivo y complejo es el problema creado a la educación por la ausencia de una lengua cuyo uso pueda constituir un eficaz medio de entendimiento en todo el país. Nunca lo fue el español, pues la dominación hispánica cumplió una finalidad evangelizadora, que los clérigos atendieron en las lenguas nativas, porque su conocimiento y su empleo les permitía calar más hondo en el alma de los neófitos; y mantuvo un carácter señorial tan acentuado, que las poblaciones indígenas no aprendieron jamás el español necesario para el coloquio, y sólo asimilaron un vocabulario limitado a los utensilios de trabajo, el menaje doméstico y las disposiciones cotidianas. No ha llegado a serlo el inglés, aunque durante media centuria fue impuesta su enseñanza en las escuelas, porque el alto porcentaje de analfabetismo redujo los alcances de su difusión, y las masas hubleron 
de conservar en su expresión la forma idiomática local. No lo es tampoco una determinada lengua nativa, porque las migraciones históricas y los accidentes naturales del país han creado numerosas diferencias dialectales, que la tradición ha perpetuado aun convirtiéndolas en un recurso propicio a la defensa contra las penetraciones adversas. $Y$ ante un hecho tan notorio, que debilitaba los vínculos sociales y culturales del país, decidióse propender a la formación de una lengua nacional, que pudiere servir al pueblo para la expresión de sus sentimientos. Como base de ella se ha designado al tagalog, enaltecido por su identificación con las tradiciones patrióticas y por una apreciable literatura escrita; pero al mismo tiempo se ha dispuesto habilitar como medios de instrucción aquellos dialectos que fuesen hablados por más de 500,000 personas, a fin de centralizar en ellos las modalidades lingüísticas regionales y tender hacia la unidad idiomática mediante la metódica incorporación de sus aportes en la lengua nacional.

Durante los dos primeros años, la enseñanza debe efectuarse mediante el empleo exclusivo de uno de los ocho dialectos predominantes entre la población cristiana, a saber: tagalog, ilocano, bicol, pampango, y pangasinan, hablados en diferentes regiones de Luzón; y cebuano, hiligaynon y samar-leyte, hablados en las islas centrales del archipiélago -llamadas Visayas- y en algunas zonas de Mindanao. Por añadidura se podrá utilizar también el tau-sug, que es el dialecto más difundido entre la minoría mahometana; y el "ibanag, hablado por la más importante minoría cultural de la población cristiana, en una pequeña región bordeada al norte y al oeste por los mantenedores del ilocano, y, en consecuencia, presumiblemente sujeto en su desarrollo a la influencia de éste último. Pero desde el tercero hasta el sexto año el único medio de instrucción debe ser el tagalog, cuyo aprendizaje se considera fácil, por haberse comprobado que los dialectos principales incluyen un abundante acervo lexicológico de aquel: pampango, 59.6 por ciento; cebuano, 48.2 por ciento; hiligaynon, 46.6 por ciento; bicol, 39.5 por ciento; e ilocano, 31.1 por ciento. El objetivo didáctico es evidente: lograr que el niño pueda representar en signos fonéticos las palabras de su lenguaje familiar, y dar a éste la fijeza indispensable para trasmitir conocimientos; y conducirlo luego hacia el dominio del tagalog, como expresión de la unidad nacional, y como medio de seguir la enseñanza del inglés, destinado a ser la lengua docta del pueblo filipino. 
O sea, que la iniciación de la enseñanza primaria supone la provisión de textos impresos en diez lenguas vernaculares diferentes, y la formación de maestros especialmente preparados para usarlas como medio de instrucción; y su pleno desarrollo exige la concentración del esfuerzo didáctico en el tagalog. Por otra parte, es notorio que la audaz reforma ha contribuído a simplificar los problemas de expresión que antes afectaron el aprendizaje, ha proporcionado un recurso eficaz para combatir el analfabetismo, y ha fortalecido los vínculos entre el hogar y la escuela. Pero ya hemos advertido que en 1957-1958 se inscribió en el sexto año un número de alumnos equivalente al 36.88 por ciento de los que entonces cursaban el primero; y, en consecuencia, nos parece reconocer que la ambicionada unificación lingüística se halla en estrecha relación con la absoluta obligatoriedad de la enseñanza primaria, y será obstruída por las condiciones económicas que predominan en la agricultura e imponen a los niños su alejamiento de la escuela.

Menor, y de naturaleza distinta, es la proyección que en el proceso educativo tiene la existencia de las minorías culturales: porque éstas alcanzan sólo al 9 por ciento de la población, y cabe presumir que sus problemas específicos tendrán una gravitación limitada. Así es, en cuanto se refiere a las 59 minorías paganas, pues, no obstantel el arraigot del sus costumbres, se hallan sometidas a la influencia que sobre ellos ejercen los conductores juveniles especialmente capacitados en los centros avanzados del país, y los métodos de trabajo que les permiten acrecentar el rendimiento de la tierra y mejorar sus utensilios. Pero la situación no es tan simple cuando afecta a los musulmanes y los chinos: porque los primeros reconocieron la soberanía filipina sólo en la segunda década del presente siglo, y, tanto su actitud religiosa como su posición en el extremo meridional del archipiélago, los vincula a los nuevos estados que en el sudeste de Asia si: guen las inspiraciones del Korán; y porque, no obstante su condición de extranjeros, es tan antigua la penetración de los chinos en el país y tan intensa su fusión con las poblaciones nativas, que todos los cálculos pertinentes a su número son considerados inferiores a la realidad, y no deja de tener una grávida significación el hecho de que mantengan sus propias instituciones económicas y sociales y su propio sistema educacional. En el primer caso, la acción educativa del estado tiende a evitar el aislamien- 
to con el cual respondieron las minorías paganas a la vulgar incomprensión de sus formas de vida, así como las inconvenientes distorsiones que en éstas puede ocasionar una trasculturación brusca; en el segundo caso procura mitigar las fricciones determinadas por las discrepancias religiosas $\mathrm{y}$, respetando el islamismo, conduce hacia el afianzamiento de los vínculos basados en la ley; y en el tercero extiende las normas de la hospitalidad a la tolerancia de los ajenos moldes culturales, para comprometer así la lealtad que los foráneos deben a las instituciones del país.

Es claro que, no obstante la diversidad de los problemas enumerados y sus respectivas soluciones, la educación primaria está destinada a preparar la superación de los desniveles estructurales y a consolidar las bases de la integración social en Filipinas. Sus limitaciones y frustraciones obstruyen el proceso de la democracia en el archipiélago, y sus necesidades hacen ostensible el desequilibrio de los elementos que ella pone en juego. Para comprenderlo mejor, volvamos los ojos a la estadística: durante el año 1957-1958 cursaron la educación primaria, en las escuelas del estado, 3'555,251 alumnos, y en las escuelas privadas sólo 160,307, - sea, el 4.5 por ciento; pero, en cambio, se inscribieron 227,673 estudiantes en las escuelas secundarias del estado, y 364,324 sea, 160 por ciento- en las escuelas secundarias privadas; y en las universidades y las escuelas superiores del estado hubo 35,802 alumnos, y 216,771 en las universidades y escuelas superiores privadas, o sea, 605.4 por cientoinDe ello es posible deducir que, por ser insuficientes los recursos que provee el trabajo asalariado, la promesa cultural ofrecida a la masa de la población en la escuela primaria, no llega a convertirse en una realidad; que, muy lejos de propender la educación al desarrollo y la madurez de una clase media ilustrada, existe la posibilidad de que contribuya a formar un vasto proletariado intelectual; que la formación cultural de los grupos destinados a dirigir el estado se efectúa bajo una débil e indirecta vigilancia de éste, y no obedece a las perspectivas del crecimiento nacional sino a una anárquica iniciativa individual.

En tales condiciones, la educación no soluciona los problemas ligados a las expectativas de progreso. Su orientación y su eficiencia, y aun menudas cuestiones de horario escolar, son discutidas públicamente, con acentuada severidad; motivan encuestas; dan tema a frecuentes pronunciamientos de la prensa cotidia- 
na, conferencias y libros. $Y$ se dice que está en crisis. En efecto: durante un examen exploratorio, al cual fueron sometidos, el año 1958, cuatro mil alumnos del quinto y sexto años de educación primaria, en una provincia situada al oriente de Luzón, el 50 por ciento alcanzaron a resolver cinco de los diez problemas de aritmética que les fueron propuestos, y sólo el veinte por ciento pudieron escribir una sencilla carta de invitación; la escuela secundaria, juzgada como el más débil eslabón en el sistema educativo, se halla igualmente afectada por el bajo rendimiento y la creciente indisciplina de los alumnos; y las instituciones de enseñanza superior son reveladoramente mencionadas como "diploma mills". Pero ¿acaso no son estos hechos un reflejo de la dinámica social? ¿Y de la lentitud con que las instituciones se adaptan a las pujantes formas de la vida actual? Basta recordar que durante el año 1937-1938 estudiaron 1'738,868 alumnos en las escuelas primarias y secundarias del estado, y $3^{\prime} 781,376$ — sea, 217.45 por ciento- en 1957-1958; que el número de escuelas y de maestros aumentó, en el mismo lapso, de 10,926 a 27,305 -o sea, 249 por ciento-, y de 38,006 a 100,471 -o sea, 264 por ciento-, respectivamente. Así se explica el origen de la crisis. Es una crisis debida a la progresiva incorporación de capas demográficas hasta ahora carentes de una tradición escolar, y cuya presencia influye: 19 , sobre las cantidades que el presupuesto nacional destina al sostenimiento de lá educción pública; $2^{\circ}$, en el nivel general de las enseñanzas icorrespondientes "a las diversas etapas de la formación individual; y $3^{\text {? }}$, en la predominante orientación de las actividades docentes conforme a las pautas de un practicismo que tiende a mejorar las ocupaciones técnicas.

En efecto, durante el año fiscal de 1958-1959, el presupuesto nacional ascendió en Filipinas a 892'057,713 pesos, y de ellos fueron dedicados a la educación pública 222'609,185; o sea, 24.5 por ciento. Pero, no obstante su importancia, esa suma es juzgada insuficiente, en atención a los siguientes hechos: 19, apenas otorga a los maestros un sueldo mínimo de 140 pesos mensuales, que supera ligeramente el jornal mínimo de 4 pesos asignado a los obreros, y no les permite ocupar una posición decorosa en la vida social, ni satisfacer debidamente las necesidades personales y familiares; $2 \%$, obliga a proveer el costo íntegro de la enseñanza secundaria mediante los pagos de los alumnos, y atiende a la gratuidad de la enseñanza primaria dentro de las limitaciones antes 
explicadas; $3^{\circ}$, no permite desarrollar un plan de edificaciones escolares, y ordinariamente se debe requerir la cooperación vecinal para dotar de locales nuevos a las escuelas, como sucede en las comunidades rurales. La educación está enderezada a preparar las energías que exige el desarrollo del país, y en ella están involucrados 4'749,359 estudiantes y maestros $\longrightarrow$ sea, 20.8 por ciento de la población-; por ello deben reclamar las autoridades una adecuada provisión de fondos para superar las actuales manifestaciones de la crisis educacional.

Aún pueden agravarse los problemas de la administración escolar, porque se pretende que las deficiencias del aprendizaje pueden solucionarse en la enseñanza primaria mediante la agregación de un año a los seis del ciclo en vigencia. Y, con la respectiva autorización, algunas escuelas privadas ensayan la extensión del currículum a ocho años. En tal período se consagra la mayor atención a los estudios de lenguaje - que incluyen pronunciación, deletreo, lectura y escritura- y a los trabajos vocacionales; y sólo la mitad del tiempo disponible se aplica a nociones de aritmética, educación social -que tiende a formar el carácter y la conciencia cívica-, higiene y ciencias naturales, música y educación física. A continuación, los estudios secundarios ocupan cuatro años, divididos en dos ciclos, respectivamente definidos como general y de especialización académica o vocacional. La mayor parte del tiempo se dedica en ellos a inglés, tagalog, educación física y entrenamiento pre-militar, y ocupaciones vocacionales; y el currículum abarca además literatura inglesa, Matemáticas, ciencias - dos cursos generales en el primer ciclo y, luego Biología y Física-, Historia —a saber: Historia y Gobierno de Filipinas, Historia de Estados Unidos, Historia de Oriente e Historia Universal-, economía y español. Se establece en el segundo ciclo la diferencia entre las dos orientaciones posibles, exonerando de las ocupaciones vocacionales a quienes han de seguir estudios superiores, y asignándoles cursos adicionales de inglés, Historia o Matemáticas; $y$, en el caso contrarlo, suprimiendo en el último año los cursos de inglés y literatura inglesa, ciencias e Historia Universal, así como recortando el tiempo destinado en todo el ciclo al tagalog y la educación física, para dar margen a una intensa práctica vocacional. En verdad, la formación cultural parece subestimada; $y$, aunque plausible, el propósito de conferir al proceso educativo una finalidad inmediatamente uti- 
litaria, parece disminuir el interés del clumno por las disciplinas que preparan el desarrollo de su mente; y si a ello se agrega el impacto del cine, el periodismo gráfico y la televisión, habría de comprenderse la inestabilidad emocional que los catones de la prensa destacan en la juventud, así como los problemas concernientes a la disciplina y el rendimiento de la escuela. De allí que la minoría china haya adoptado un sistema escolar distinto, caracterizado por haber extendido los estudios secundarios a seis años, omitir la especialización vocacional y poner el énfasis en las materias culturales - geografía, historia y literatura de China, Historia del Mundo en la Edad Moderna, Algebra aplicada, Geometría Analítica, Trigonometría y Química-, según aquellos viejos ideales que basan la educación en la autoridad y la preparación de la madurez.

Tal vez pueda estimarse que el más intenso aliento de la escuela es, a un mismo tiempo, su más notorio defecto. Porque la organización de su trabajo se inspira estrictamente en las actividades y las necesidades de la comunidad, y tiende a desenvolver la habilidad prórtica y las cualidades morales que puedan conducir al alumno en la vida cotidiana. Y ello basta para justificar las deserciones, pues tanto los estudiantes como sus padres esperan una profunda diferencia entre la escuela y la comunidad, para estimular un continuado empleo de tiempo y dinero; e ingenuamente conšideran queilaslenseñanzasodel hogar y de alguna labor remunerativa pueden sustituir a las que imparte la escuela para propulsar la vida de la comunidad. Y como en materia vocacional es posible que el maestro no se halle en aptitud de otrecer una experiencia semejante a la que poseen quienes ejercen la actividad productiva que aprendieron de sus mayores, o que la escuela no disponga de los implementos y materiales requeridos en el aprendizaje, es explicable que el interés por la educación escolar no sea muy intenso, ni duradero. Por eso se discute la conveniencia de tonificar el currículum, mediante el restablecimiento del sétimo año que en 1940 fue suprimido de la educación primaria, y aun de hacer efectiva la obligatoriedad de la concurrencia a la escuela; pero toda providencia definitiva está condicionada por la provisión de los fondos correspondientes, y la orientación práctica dada a la formación de la niñez gravita sobre la debilidad de la enseñanza secundaria y limita la hondura de los estudios superiores. $Y$ al mismo tiempo se hace más intensa y 
sensible la expectativa que promueven las posibilidades de progreso individual y social ligadas al desarrollo de la educación.

\section{VARIACIONES SOBRE EL BAMBU}

Vamos a visitar las cataratas de Pagsanjan, situadas a 102 kilómetros de Manila y que la fama proclama como uno de los más pintorescos lugares de Filipinas. El camino corre a escasa distancia de las riberas del Lago Bay, cuya discreta brisa mitiga el intenso calor de la estación; se desliza entre fecundas plantaciones de arroz, extensos bosques de cocoteros, esbeltos bambúes y frondosos mangos; y su cinta parduzca es apenas una leve herida en el verdor del horizonte. Aquí y allá, perdidas entre los árboles, asoman las casas de los poblachos que el camino ha congregado y a cuya vera flamean las ropas multicolores tendidas al sol o se amontonan los frutos recién desprendidos. De tarde en tarde, descuella en el paisaje la silueta gris de los carabaos, que hozan plácidamente entre las hierbas, o miran con ternura a los viandantes mientras un niño va a horcajadas sobre su lomo, o arrastran el arado que dispone las entrañas de la tierra para acoger la semilla fecunda, o proyectan su inofensiva cornamenta en la claridad del cielo.

A vęces parece que las líneas del contorno están condicionadas por el frágil y altivo manojoide bambúes, que desde un punto se inclinan hacia todas partes. Y el hombre ha sabido cautivar la sencillez y la propicia utilidad de sus flexibles tallos, para dar a su propia vida un marco sobrio y amable. Sobre pilares y vigas de madera, los campesinos forman el piso y las paredes de sus hogares con delgados fragmentos de bambú; la escalera, el barandal que a veces mira al camino, y mucho de su menaje, es también de bambú; y reposan sobre el piso, que se cimbra plásticamente bajo el peso del cuerpo laxo. En el caserío rural suele haber también alguna capilla, sin ornamento alguno, abierta $\alpha$ las caricias del viento, y donde llega algún clérigo para oficiar cuando la Iglesia lo prescribe; humilde y rústicamente, su altar está formado por algunas varas de bambú sobre las cuales extiende el sacerdote su albo lienzo; y cuando no es sobre la tierra, los fieles doblan las rodillas sobre reclinatorios de bambú. De un lado a otro del camino se extiende a veces un ostentoso cartelón de propaganda política, sostenido por una habilidosa urdimbre de 
bambú; a la entrada de los pueblos álzase una armazón de bambú, en la cual se ofrece a la vista de los viajeros una salutación de bienvenida; y para dar cauce rítmico a la alegría o a las palabras de alguna canción popular, la percusión del bambú ofrece una penetrante y graciosa sonoridad.

Cuando los pueblos lucen aires de ciudad suelen tener una hermosa iglesia cuyos muros de piedra se alzan frente a una hermosa plaza, o dominan las casas desde una eminencia del terreno; y una amplia escuela, integrada por dos o tres edificios a los cuales llegan generosamente la luz y el aire; y un barracón destinado a los espectáculos cinematográficos; y algunas calles transversales, donde los artesanos fabrican objetos de uso tradicional y algunos comerciantes echan al viento los dudosos acordes de una trasmisión radiofónica; y uno o más puestos donde algún policía dirige la circulación de vehículos. Así es Pagsanjan. Pero aquí se encuentra además un acogedor establecimiento, que ofrece al visitante sombra Y retiro en sus ascéticas habitaciones de bambú, y mira hacia el río que nace al pie de las cataratas.

Es preciso aventurar la travesía de la corriente sobre una canoa, tripulada por dos ágiles mestizos, y recorrer la sinuosa extensión de una garganta. Al comienzo es plácido el curso del río, y la mirada se detiene a contemplar las plantas acuáticas, o la exuberante arboleda que selempina abruptamente sobre las cuestas de ambas márgenes, o las flexibles lianas que persiguen el destino de los altivos troncos. La corriente, lleva en silencio algunos frutos prematuramente desprendidos de los cocoteros. Entre las ramas se oculta presurosa alguna iguana, o grita su temor algún mono esquivo. Al frente, un rápido obstruye la perspectiva de la navegación, y los bogas abandonan la canoa para empujarla hacia adelante y vencer así el obstáculo. Pero éste no es el único, y muy diestramente saben sortear los mestizos aquellas seductoras dificultades de la naturaleza: entre pesadas rocas cuya separación deja estrecho paso a la canoa; o deslizando ésta sobre un tubo de metal, que evita las peligrosas aristas en un curso torrentoso; o aproximándose a una oquedad de la rivera, sobre la cual se esparce un leve chorrillo. Y, al fin, he allí las cataratas.

Una accidentada escalera de bambú, flanqueada por un oportuno barandal, conduce la inquietud hacia la cumbre, para 
contemplar el nacimiento y los pasos del plateado torrente. La fatiga del ascenso puede ser mitigada sucesivamente en tres casetas de bambú, en torno a las cuales se cierne la sombra rumorosa de la vegetación; y en tanto que desde la primera se mira los contrastados colores del paisaje ornado por la catarata, es necesario llegar a la tercera caseta para ver cómo discurre el agua por el llano, cae en forma abrupta, corre brevemente en agitado torbellino y se precipita hacia la garganta. A corta distancia de la caída forman las rocas un dique natural, a cuya vera quedan protegidas las canoas. $Y$ al otro lado se extiende un vasto remanso, circunvalado por las alturas verdeantes, y presidido por la altiva y sonora voz del agua. Allí aguarda una balsa, formada por una triple hilera de bambúes. Sobre ella nos aproximamos al pie de la catarata, conducidos por unos balseros mestizos que tiran de una liana prendida a las rocas, y penetramos en una pequeña cueva situada detrás del torrente. Su estruendo es amplificado por las paredes rocosas; y, mientras recibimos la frescura de sus caricias, miramos cómo se irisa a través de ella la espléndida luz del sol.

Cuando volvemos al remanso, y en la canoa surcamos la corriente que extiende su sinuoso curso por la garganta, las imágenes son ya familiares. Pero aún se nos revela con mayor nitidez la belleza de aquel rincón del mundo, donde la naturaleza ha reunido los elementos de su gracia y el hombre ha tenido el acierto de respetarlos. "Jorge Puccinelli Converso"

\section{UN "BARRIO" EN FILIPINAS}

"Barrio" no es, en Filipinas, un sector de la ciudad. Es un vecindario rural. Avizoramente situado sobre las márgenes de una carretera, o agazapado tras una huella serpeante, o perdido entre una próspera arboleda, el "barrio" es siempre una comunidad de campesinos honestos y hospitalarios. Pero fácilmente ha cundido entre ellos la rebeldía, cuando una insólita situación ha quebrado el apacible ritmo de su vida. Y la violencia ha esparcido sobre la tierra sus despojos, en forma esporádica y sorpresiva, pero tenaz y silenciosa, aun en la punta de una flecha o en la rutilante nerviosidad de un cuchillo. Por ejemplo, de ellos salieron las masas que siguieron a los líderes patriotas en su lucha contra el dominio español, y en su bandera inscribieron un lema en 
la lengua hablada por el pueblo. Un maestro norteamericano ha referido que en los días iniciales de la ocupación debía lucir su revólver al cinto, cuando salía cada mañana para desempeñar su misión en la escuela de un "barrio". Sus gentes proporcionaron víveres y hombres a las guerrillas que durante la If Guerra Mundial hostigaron a los invasores japoneses. $Y$ muchos mantuvieron las armas en sus manos hasta no ser beneficiados con una parcela donde pudieran lograr una segura parte de la libertad y la felicidad conquistadas por el país. Sin embargo, no se crea que la violencia interrumpió la quieta existencia del "barrio". Fue sólo un matiz en la cotidiana lucha por el pan, que transitoriamente debía ligarse a la defensa de la vulnerada dignidad del hombre. $Y$ las pasiones enardecidas volvían pronto a su cauce rutinario, a su oscura y mínima esperanza.

En los "barrios" imperan las altivas y livianas casas de "ni$\mathrm{pa}^{\prime}$ ", que desde tiempo inmemorial dan albergue a las gentes de Filipinas. Edificadas sobre una fundamental armazón de madera o de bambú, sus paredes laterales se encuentran formadas por ligeros tabiques donde se entrecruzan las largas hojas de "nipa", y ostentan techo inclinado de lo mismo y piso de bambú. Constan de un solo recinto cuadrangular, dividido por movedizos paneles de "nipa" o bambú, que pueden conferir extraordinaria versatilidad a todo el interior; y así presentan un ambiente principal, los cubículos "necesarioscparalios dormiforios, y un espacio exterior destinado a los quehaceres domésticos. Su menaje suele ser muy escaso y - con alguna frecuencia- de fabricación casera: una rústica mesa, que el uso ha hecho grisácea, y en torno de ella algunos bancos; unos petates, enrollados en algún ángulo durante el día, y que por la noche se tienden sobre el suelo de bambú para aliviar el reposo; cama y ropero, que indican ya cierta bonanza familiar; una airosa repisa, con adornos que hacen burla de la pobreza circundante o con algunas piezas de vajilla; un baúl, que guarda prendas y trebejos; y en la cocina, fogón y ollas de barro cocido. Todo luce bastante limpio, pues sólo así puede evitarse en el campo la asidua concurrencia de los insectos; y libre de la humedad que dejan las lluvias, pues la estructura entera se halla algo elevada sobre el nivel del suelo.

Aquellas "casas de nipa", cantadas por los poetas como asilo de la sinceridad y de la paz, no son siempre iguales. Tienen una escalera de bambú, que da acceso directo al recinto interior 
o a una pequeña galería; y ésta, sombreada por un alero y bordeada por una baranda de bambú, denota por sí sola el relativo confort de que disfrutan los moradores. Algunas utilizan como depósito o corral el espacio protegido por la casa, y allí se ve los frutos que deberán ir al mercado, o los carabaos, cerdos y gallinas que retozan en plácida armonía; pero otras dedican aquel espacio únicamente para guardar una carreta u otro vehículo, y a corta distancia tienen para esos efectos una construcción auxiliar, cuya parte alta sirve como granero. En aquellas deben ser abiertas las ventanas, para que la luz del día no se detenga; pero en éstas se filtra suavemente, a través de las delgadas y graciosas láminas de concha que las adornan. Y no faltan además los indicios de una gradual adaptación a los cambios culturales, que fácilmente se advierten en la utilización de la madera, la calamina $\circ$ el vidrio, para cubrir los lados de la casa, los techos y las ventanas. De manera que basta observarla ligeramente, para reconocer el nivel económico, social o cultural de quienes habitan aquellas rústicas viviendas; y para comprobar las diferencias que en su aldeana sencillez alberga el "barrio".

Allí no hay instalaciones higiénicas. Para asegurar la provisión de agua potable se ha empezado a perforar pozos artesianos; pero a falta de éstos se almacena el agua de la lluvia, o se utiliza prudentemente la que da el río, o para beber se apela a la del coco. Según los casos, proveendos vecinoseal trasporte y la reserva del líquido que sus necesidades exigen, empleando grandes cántaros de barro cocido o largos y gruesos troncos de bambú, en los cuales son previamente removidos los nudos. Y, cuando las emanaciones orgánicas malogran el ambiente, las casas enteras son trasladadas con la ayuda generosa del vecindario, pues basta desenterrar sus pivotes y portarlas en los hombros. Varias veces pueden cambiar así de emplazamiento $\mathrm{y}$, aunque dentro de los linderos de una parcela, es claro que tal movilidad confiere al "barrio" una versatilidad muy peculiar. Por ello no es posible reconocerle una traza urbnna. Y, aparte de la línea imperativa que fija el camino, las "casas de nipa" son levantadas en el lugar adecuado para dominar la parcela. Destacan pálidamente en el agreste contorno del "barrio", porque agregan una tonalidad opaca a los brillantes matices del paisaje; pero no es posible disociar su modesta estructura y la airosa silueta de los árboles, y la imaginación cree que se reclinan ante los troncos enhiestos para agradecer los dones de la tierra. 
Cada hacienda alberga a sus labriegos en uno o más "barrios", cuyas "casas de nipa" los vinculan al trabajo; pues, no obstante ser éste muy poco remunerativo, les permite asegurar la vivienda familiar aun durante los largos meses en que la naturaleza prepara sus frutos. Algunas zonas de cultivo son confiadas a tenants o aparceros, que prodigan su esfuerzo por incrementar así sus propias utilidades. Y hay también en los "barrios" una variedad de pequeños propietarios que trabajan su propia tierra, o al mismo tiempo fungen como tenants, o son jornaleros ocasionales. Pero a todos $-a$ "los que viven por sus manos y los ri$\cos ^{\prime \prime}$, según dijera el poeta medioeval-, a todos beneficia la extraordinaria fecundidad del suelo, y muchos dicen que solo es comparable a la del paraíso bíblico. Unos se refieren a ella con admiración y gratitud, en tanto que los ahitos dicen que incita a la indolencia. Lo cierto es que difícilmente podrá hallarse algún rincón donde no señoreen sus presentes y, de manera predominante, el coco y el bambú. La corteza leñosa del primero es el combustible de las cocinas hogareñas, luce flores en las ventanas, y su concavidad es a veces adoptada para fabricar tasas y copas vistosas: su agua es empleada para beber y condimentar dulces, puede trocarse en vinagre o licor, y da a las mozas el aroma del propio fruto cuando la emplean para lavar o untar sus cabelleras; el fruto es elemento de una versátil culinaria y su grasa tiene numerosas aplicaciones industriales; del tronco se obtiene una especie de harina; "Ylas hojas cubren lo' techos de las casas o proporcionan unas flexibles varitas que se usan en cortinillas y tapetes. Los esbeltos y resistentes tallos del segundo forman la estructura de las casas campesinas, dan la materia básica de preciado mobiliario y de adornos muy decorativos, se acoplan prontamente para facilitar labores de albañilería y eventuales armazones de ciertos días festivos, aparecen sobre el mar como estabilizadores de las inestables canoas, y prestan su resonancia a las cuerdas de algún instrumento popular o a los pasos rítmicos de los bailes campesinos.

Más que en la calidad heterogénea de las ciudades, el carácter de la sociabilidad filipina se encuentra en los "barrios": porque sus formas de vida afectan a las mayorías del país, mantienen al hombre elementalmente sujeto a la naturaleza, y determinan los orgullosos localismos que se manifiestan aun en la diversidad de dialectos. En ellos puede comprobarse la supervivencia 
de remolas tradiciones y la acción estimulante de quienes preparan el cambio necesario. No es posible anticipar si podrá estimularse el desarrollo de la pequeña propiedad, $u$ organizarse un vasto movimiento cooperativo, o industrializar la producción $\alpha$ graria. Pero ya se discute la posibilidad de tal cambio y la conveniencia de planearlo metódicamente, para evitar ensayos aventurados o transformaciones que pueden ocasionar un desequilibrio.

\section{PRESENCIA DEL AMOK}

Difícilmente puede apreciar un forastero lá estabilidad de los cambios sufridos por el carácter de un pueblo agitado por alguna crisis histórica; o definir la profundidad de sus tendencias tradicionales, entre las formas de vida que se imponen a la observación. Sobre todo, cuando esa crisis ha sido tan compleja y prolongada como en el caso del pueblo filipino, que durante varias décadas ha mantenido su beligerancia contra el dominio español y la ocupación norteamericana, ha culminado su lucha contra la agresión japonesa, y se halla situado en una estratégica zona en la cual se cruzan las influencias de Oriente y Occidente. Sus gentes son tan amigables y cordiales, como los hombres de buena voluntad que existen a través de todo el mundo; pero el cumplimiento de su destino los ha conducido hacia los senderos de la violencia, y hoy es frecuente coscuchar noticias y prevenciones alusivas a sus excesos. Por ejemplo: a unos metros de la Catedral de Manila -donde ha sido improvisada una barriada sobre las ruinas que dejó la guerra-, cayó un sujeto herido por una flecha, tan silenciosa y mortalmente, que fueron inútiles las pesquisas policiales encaminadas a identificar al responsable; se aconseja evitar el tránsito nocturno de las carreteras interiores, porque entre las frondosas arboledas acechan bandidos que obstruyen las vías para asaltar a los viajeros; en los edificios públicos, las oficinas bancarias y algunos lugares de esparcimiento se ve carteles que prohiben el uso de armas de fuego en su interior y plden se las deposite en la portería o la administración ${ }^{1}$. Todo ello

1 City Hall: "Fire arms not allowed inside the... Deposite your fire arms to Police". National Science Development Board: "Deposite all fire-arms and other deadly weapons here". Bowling: "Gambling \& fire arms strictly prohibited"; "Please deposit fire arms to the Manager". 
anuncia la coexistencia de la civilidad y de costumbres que contrarían sus fines. $Y$ sugiere que el límite entre unas y otras puede ser, en ocasiones, sumamente fluido, como lo fue la posesión de la tierra durante la lucha contra los agresores japoneses: pues, si la noche protegió entonces la acción de los patriotas emboscados en los campos, hoy encubre la sangre vertida con los rudimentarios y silenciosos instrumentos que la audacia de las gentes opuso en otro tiempo a la superioridad técnica del enemigo. Y quizá no sea posible establecer si así reviven costumbres ancestrales 0 se perpetúan las formas de conducta que la crisis originó.

En verdad, la índole natural y permanente, tanto como el equilibrio objetivo de la personalidad, sufren transitorio desconcierto bajo el impacto de la injusticia, la intriga o la simple impertinencia. Súbitamente puede oscurecerse entonces el razonamiento, y aún el ánimo más apacible se altera hasta un punto en que el hombre parece "fuera de si". En cambio, los pueblos de Filipinas -y de otras islas oceánicas - imaginan una influencia exiraña, y decisivamente superior a la voluntad individual, para explicar obsesiones pasionales y desmanes cuyas proyecciones quiebran el ritmo y las normas de la vida cotidiana. La llaman amok. Y sugiere la supervivencia de un mundo mágico, ante el cual vacila el pensamiento, sobrecogido por la desafiante presencia de lo desconocido.

Proyectemos nuestra atención hacia algunas escenas que revelen su intensidad y su carácter. Pequeño, cetrino, descalzo, tan ágil y cauteloso como un felino, abandona a veces un negrito la alta espesura donde habita, irrumpe en algún poblado cuando ha caído la noche, y al tropezar con un viandante desnuda una mortífera hoja, traza en la sombra una curva destellosa, y deja en el suelo una víctima inocente. Es el amok. Sale el moro de la ceremonia propicia, con cierto brillo colérico en la mirada, recio el andar y el ademán tenso; halla en su camino un cristiano desaprensivo; y desde los revueltos pliegues de su vestidura emerge entonces el afilado kris, para consumar el sacrificio que la ley del profeta exige a los guerreros. Es el amok. Si después de uñ noche alegre, o excitado por los tonos de una discusión doméstica, o agobiado por la desesperanza que origina la miseria, alguien se revuelve con violencia y siega las vidas de amigos 0 familiares es, también, a causa del amok. Y si un hombre quie- 
bra las bases del sentimiento familiar y de la conveniencia personal, tanto como la habitual regularidad de su conducta, para seguir tras el amor de una mala mujer, es, también, por el amok. Toda viclencia que rompa los cauces del afecto o el respeto, o los actos cuya comprensión escapa a las convenciones usuales, se piensa que obedecen al extraño y transitorio poder del amok. Cuanto excede el equilibrio de la conciencia, es visto como manifestación de la energía desbordante que infunde el amok. Y no importa que la razón haya establecido calificaciones precisas para los hechos a cuyo juzgamiento debe enfrentarse, pues ocurre que a veces se amortigua la voluntad del hombre, por efecto de una imposición social o merced a un concierto de circunstancias que deforman sus afinidades íntimas. Pero una contingencia no cambia la naturaleza invívita de la persona: sólo la somete a una compulsión que sofoca su libertad, y cuando aquella pasa debe entenderse que el individuo torna a sí mismo. Por tanto, revelaría ser muy superficial quien asimilase el amok a la enajenación; o quisiera verlo como la explicación que el pensamiento primitivo elabora ante las formas anómalas de la conducta; o creyese que es una ficción enderezada a mitigar la responsabilidad consiguiente a un acto criminal. Hablar del amok supone reconocer que los hechos del hombre están sometidos a la ley de su grupo, y que la eventual comisión de una violencia obedece a la afirmación y la defensa de una personalidad colectiva frente a las agrupaciones presuntamente hostiles.

Muy ilustrativos nos parecen dos episodios, respectivamente protagonizados por un misionero y un general. Referidos como anécdotas que demostrarían la incomprensión de los llamados pueblos primitivos, ante las más elocuentes demostraciones de las excelencias de la civilización occidental, nos parece que confirman la preeminencia que ellos reconocen a sus principios espirituales y sociales, así como su relativa impermeabilidad a toda compulsión enderezada a cambiarlos o desconocerlos. En efecto, cuenta el primero que en una oportunidad fue llevado por su misión evangélica hasta un lugar habitado por tinguianos, y dirigiose al más anciano para exponerle los fundamentos de la doctrina cristiana; habló en forma tan sabia y expresiva, tan dulce y magistral como su experiencia le aconsejaba; parecíale que sus palabras lograban efecto convincente, pues aquel entornaba su mirada y con aparente humildad inclinaba el rostro, y ya presumía 
el sacerdote que tras de su conversión habría de seguir la del pueblo; pero después de meditar un momento arguyó el jefe tinguiano que a la voluntad divina debfan la posesión de aquel rincón del mundo, tanto como las creencias que profesaban, y le rogó que no pratendiese cambiar nada porque estaría mal desobedecer los designios supremos. Por su parte, el general debió dirigirse al aguerrido sultán de una isla meridional del archipiélago, cuya sujeción había requerido varios años de escabrosa campaña; y para afianzar la culminación de su victoria militar qulso ofrecer al enemigo la generosa amistad del país próspero y poderoso que lo enviaba; hizo el elogio de su civilización y su grandeza, y un cáliclo anuncio de las ventajas que podría frcmquearle el acatamiento de su ley; pero el vencido sultán proyectó sobre el general una brillante mirada, y con reprimicio ardor le pidió que renunciase a la posesión de aquella isla, donde la naturaleza era el único bien que sus hombres disfrutaban, pues nada agregaría a la riqueza y la temida potencia del gran país a cuyas armas había debido rendirse.

Los llamados pueblos primitivos no son reducidos por los alardes dialécticos ni las conquistas. Se repliegan, material y espiritualmente, apenas toman conciencia de su debilidad para mantener el aislamiento que les es grato; y, aunque ciceptan la rocepción de elementos foráneos. montíenen una indeclinable lealtad a sus usos y tradiciones, sus creencias y prácticas rituales. Por ende, tales fómás de vida constifuyen vínculos de solidaridad social, cuya supervivencia determina la perpetuación del grupo; por razones de gobierno, su preservación suele dar origen a procedimientos esotéricos, que las hacen eficaces como medios de identificación; $y$ en el ciclo vital masculino adquiere significado sustantivo la fiesta de iniciación, que hace al hombre partícipe de los secretos del grupo y le impone la responsabilidad de asumir su defensa. Si descarga entonces la violencia para cumplir alguna tarea, lo hace bajo el imperio de su propia ley, para afirmar la vitalidad del cuerpo social y quizá para vengar ofensas y despojos. Es el amok.

Deparlamento de Historia

Universidad de San Marcos 